\title{
Cardiac imaging at 7.0 T: comparison of pulse oximetry, electrocardiogram and phonocardiogram triggered 2D-CINE for LV-function assessment Tobias Frauenrath ${ }^{* 1}$, Wolfgang Renz ${ }^{2}$, Nishant Patel ${ }^{1}$, Fabian Hezel ${ }^{1}$, Matthias Dieringer ${ }^{1}$, Jeanette Schulz-Menger ${ }^{3}$ and Thoralf Niendorf ${ }^{4}$
}

Address: ${ }^{1}$ Max Delbrück Center for Molecular Medicine (MDC), Berlin, Germany, ${ }^{2}$ Siemens Medical Solutions, Erlangen, Germany, ${ }^{3}$ Charité, University Medicine HELIOS-Clinics and Max Delbrück Center for Molecular Medicine (MDC), Berlin, Germany and ${ }^{4}$ Max Delbrück Center for Molecular Medicine (MDC) and Charité, University Medicine, Berlin, Germany

* Corresponding author

from 13th Annual SCMR Scientific Sessions

Phoenix, AZ, USA. 21 -24 January 2010

Published: 21 January 2010

Journal of Cardiovascular Magnetic Resonance 2010, I2(Suppl I):OI5 doi:I0.1 I86/I532-429X-I2-SI-OI5

This abstract is available from: http://jcmr-online.com/content/I2/SI/OI5

(c) 2010 Frauenrath et al; licensee BioMed Central Ltd.

\section{Introduction}

One important development which is looming on the (pre)clinical research horizon is the move towards CMR at 7.0 T [1]. At (ultra)highfields, the sensitivity of ECG recordings to interference from electromagnetic fields and to magneto-hydrodynamic effects increases and with it the ECG failure rate together with the motivation for a robust, practical gating/triggering alternative. Realizing the constraints of conventional ECG, an MR-stethoscope has been proposed to meet the demands of cardiac triggered MRI [2].

\section{Purpose}

Motivated by the challenges and limitations of conventional ECG together with the advantages of acoustic cardiac triggering (ACT), this study compares phonocardiogram, electrocardiogram and pulse oximetry triggered MRI for LV-function assessment at 7.0 T. For this purpose, breath-held 2D-CINE imaging in conjunction with a retrospective triggering regime was conducted.

\section{Methods}

The acoustic gating device comprises three main components: an acoustic sensor, an acoustic wave guide and a signal processing unit [3]. Short axis views of the heart were acquired with a $2 \mathrm{D}$-CINE-FLASH technique (TE $=2$ $\mathrm{ms}, \mathrm{TR}=4 \mathrm{~ms}$, matrix $=256 \times 192, \mathrm{FOV}=36 \mathrm{~cm}^{2}, 25$ car- diac phases, slice thickness) on a 7.0 T MR-system (Siemens, Erlangen, Germany) using a dedicated 4-element TX/RX cardiac coil array. Vector-ECG, pulse oximetry and ACT traces were recorded simultaneously.

\section{Results}

ECG waveforms were susceptible to severe T-wave elevation which was pronounced at the isocenter of the $7.0 \mathrm{~T}$ magnet (Fig. 1). The MR-stethoscope provided phonocardiograms at 7.0 T free of interferences from electromagnetic fields or magneto-hydraulic effects (Fig. 1) even in the isocenter. This renders ACT suitable for reliable synchronization at ultrahigh fields as demonstrated in Fig. 2. Conversely, R-wave mis-registration occurred in ECG-triggered acquisitions with a failure rate of appr. 50\% which manifest itself in a severe jitter of the R-wave recognition tickmarks (Fig. 2b). Failure to detect the onset of the cardiac cycle was reduced for pulse oximetry, though a temporal inaccuracy of the triggering of app. $20 \%$ of a R-Rinterval was observed (Fig. 2). Acoustically triggered CINE imaging at 7.0 T produced images free of motion artifacts (Fig. 3a). In contrast, ECG triggered CINE imaging was prone to severe cardiac motion artifacts if R-wave misregistration occurred (Fig. 1a). Pulse oximetry triggered 2DCINE imaging was found to be less sensitive to cardiac motion effects although the jitter in the pulse-oximetry recognition constituted a synchronization problem. 

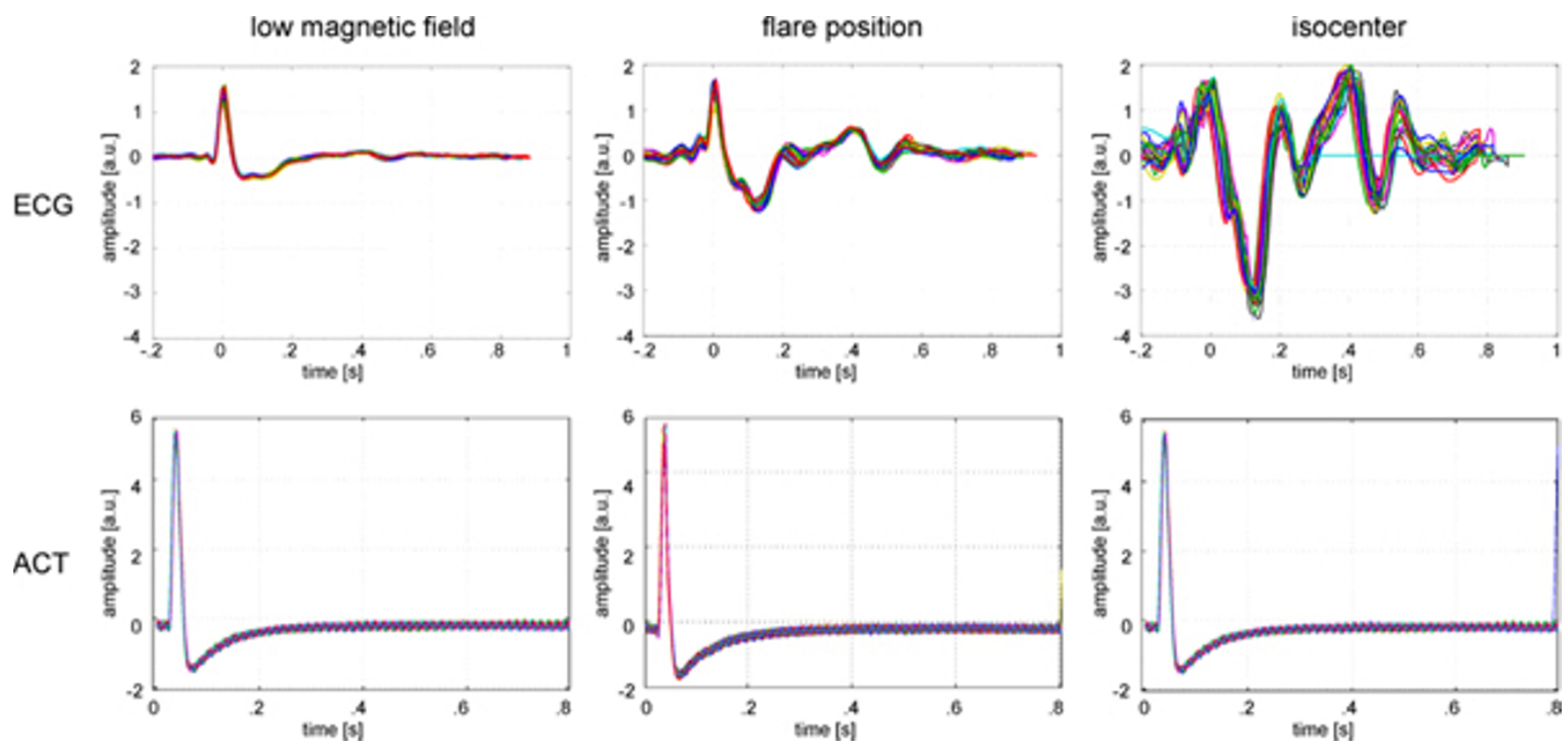

Figure I

ECG (top) and ACoustic Trigger (bottom) signal traces derived from a healthy subject. Signal traces were recorded outside (left), at the front end (middle) and in the isocenter (right) of a 7.0 T magnet. Severe T-wave elevation signal distortion occurred in the ECG signal obtained at the magnet's isocenter. In contrast, ACT is free of interferences with electromagnetic fields and magneto-hydrodynamic effects.

\section{Conclusion}

This work examined the feasibility of LV-function assessment at 7.0 T using acoustically triggered 2D-CINE imaging. ACT's superior robustness has been demonstrated by eliminating the frequently-encountered difficulty of mistriggering due to ECG-waveform distortions or temporal jittering in the pulse-oximetry synchronization.
ECG

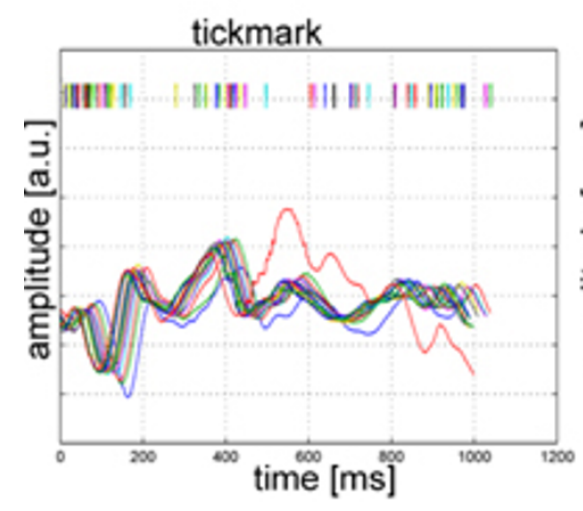

pulse-oximetry

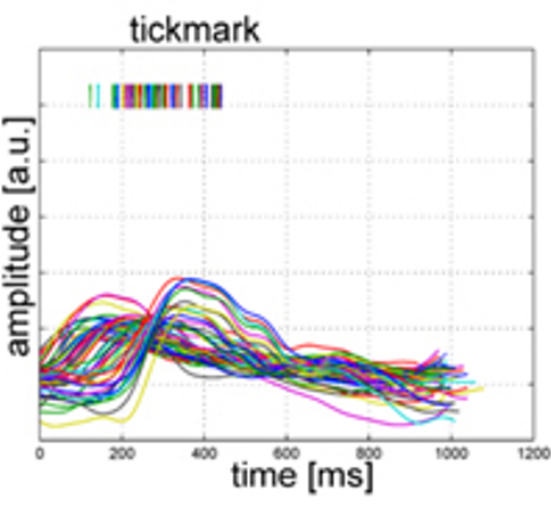

ACT

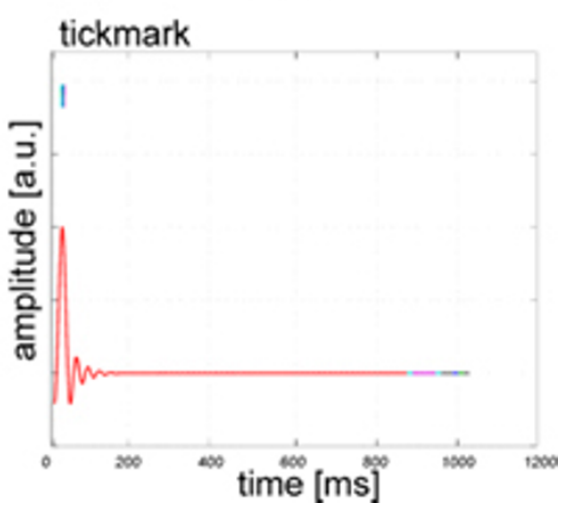

\section{Figure 2}

Traces of the cardiac activity obtained from a single subject over 208 cardiac cycles (1 6 cardiac cycles per slice times I 3 slices) using ECG (left), pulse-oximetry (middle) and acoustic (right) measurements at 7.0 T. Please note the severe T-wave elevation and signal distortion in the ECG due to magneto-hydrodynamic effects. 


\section{ECG}

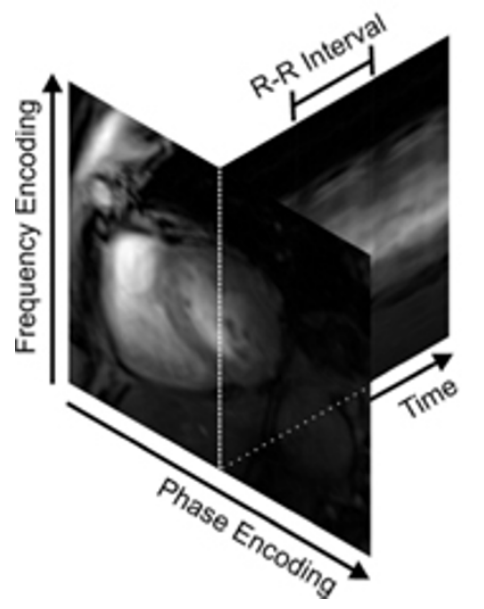

\section{pulse oximetry}

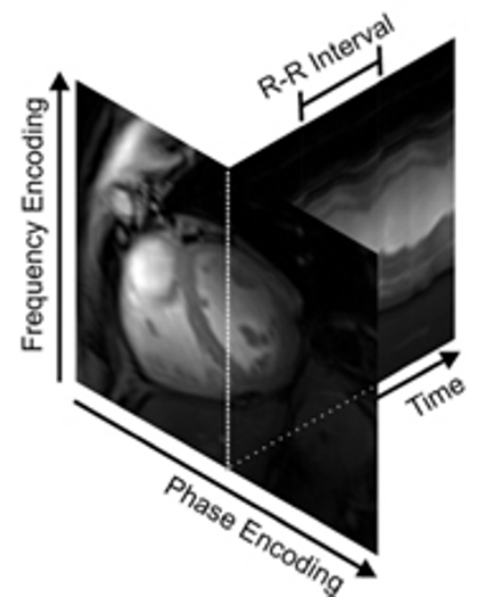

ACT

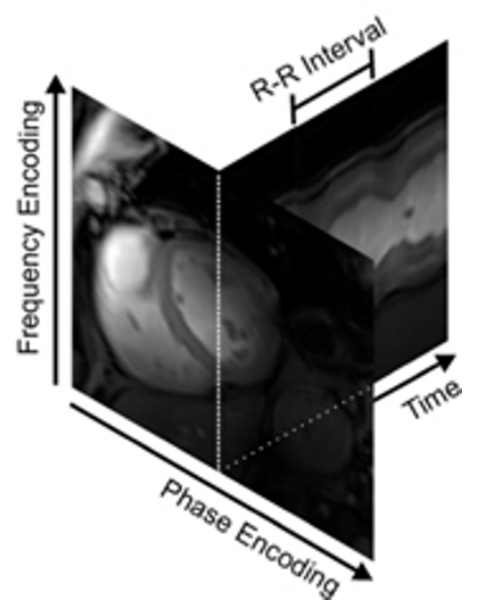

Figure 3

Short axis views of the heart together with whole $\mathbf{R}-\mathbf{R}$ interval time series of one-dimensional projections along the profile (dotted line) marked in the short axis view. Data were obtained at 7.0 T using ECG (left), pulse oximetry (middle) and acoustically triggered (right) 2D CINE FLASH acquisitions. ECG triggered CINE imaging was prone to severe cardiac motion artifacts due to R-wave misregistration. Acoustically triggered CINE imaging at $7.0 \mathrm{~T}$ produced images free of motion artifacts.

\section{References}

I. Vaughan JT, Snyder CJ, DelaBarre LJ, Bolan PJ, Tian J, Bolinger L, Adriany G, Andersen P, Strupp J, Ugurbil K: Whole-body imaging at 7 T: preliminary results. Magnetic resonance in medicine: official journal of the Society of Magnetic Resonance in Medicine/Society of Magnetic Resonance in Medicine 2009, 61 :244-248.

2. Frauenrath T, Hezel F, Heinrichs U, Kozerke S, Utting JF, Kob M, Butenweg C, Boesiger P, Niendorf T: Feasibility of cardiac gating free of interference with electro-magnetic fields at I.5 Tesla, 3.0 Tesla and 7.0 Tesla using an MR-stethoscope. Investigative radiology 2009, 44:539-547.

3. Frauenrath T, Niendorf T, Kob M: Acoustic method for synchronization of Magnetic Resonance Imaging (MRI). Acta Acustica united with Acustica 2008: I48-I 55.

Publish with Bio Med Central and every scientist can read your work free of charge

"BioMed Central will be the most significant development for disseminating the results of biomedical research in our lifetime. "

Sir Paul Nurse, Cancer Research UK

Your research papers will be:

- available free of charge to the entire biomedical community

- peer reviewed and published immediately upon acceptance

- cited in PubMed and archived on PubMed Central

- yours - you keep the copyright
BioMedcentral 